Original Research Paper

\title{
Experimental Analysis on the Running of CI Engine with Pongamia Oil-Diesel as Fuel for Exhaust Gas Recirculation (EGR) Technique
}

\author{
Abdullah Al-Ghafis and M Shameer Basha \\ Department of Mechanical Engineering, Unaizah Engineering College, Qassim University, Saudi Arabia
}

\author{
Article history \\ Received: 17-06-2020 \\ Revised: 04-07-2020 \\ Accepted: $28-07-2020$ \\ Corresponding Author: \\ Abdullah Al-Ghafis \\ Department of Mechanical \\ Engineering, Unaizah Engineeri \\ ng College, Qassim University, \\ Saudi Arabia \\ Email: a.alghafis@qu.edu.sa
}

\begin{abstract}
Present days, I.C engines are the fundamental parts of shipping and automatic farming system, etc. Hence there is an exponentially upsurge in utilization of Diesel and gasoline products. At the same time Diesel is an exhaustive source of energy and recent pitch in Diesel prices have focused interest in bio-fuels and also it has resulted that biodiesel-oiled engines produce comparatively fewer $\mathrm{CO}$, unburned $\mathrm{HC}$ and smoke emissions, but higher emissions of NOx. Exhaust Gas Recirculation is observed as best technique to reduce NOx emission in recent days as the flame-temperature inside the cylinder decreases. A one-cylinder, $\mathrm{H}_{2} \mathrm{O}$ cooled with constant speed DICI engine was used for the research. In exhaust gas quantity of $\mathrm{CO}, \mathrm{HC}$, NOx and smoke opacity was determined to estimate the emissions and to assess performance of test-rig BTE, BSFC, Air/Fuel ratio, ME, VE and EGT parameters were considered. Both for base and combination of PME performance and emission parameters were evaluated at 20\% EGR, CR 17.5 and FIP 200 bar. Collaboration of EGR with combination of PME increased concentration resulted in slightly reduced BTE, increased BSFC, decreased Air/Fuel ratio, decreased VE, increased EGT, minute decrement in $\mathrm{ME}$ and absolute lower NOx emissions, little increase in $\mathrm{HC}$ and small increment in smoke opacity. Overall, it is practical that at full load PME60 has similar or significant impact on performance and emission variables compared with baseline.
\end{abstract}

Keywords: PME, EGR, Engine Emissions, Performance Characteristics

\section{Introduction}

From the previous findings it is clear that to reduce NOx creation inside the burning chamber EGR is best technique. Exhaust comprises of major percentage of $\mathrm{CO}_{2}, \mathrm{~N}_{2}$ and $\mathrm{H}_{2} \mathrm{O}$ vapors contents. Portion of burnt gas is dispersed through the engine burning chamber; it reacts as dilutant to the combination present in combustion chamber. On the other side it also reduces the amount of $\mathrm{O}_{2}$ percentage inside the cylinder. Heat capability of the intake-charge raises causes high specific heat of EGR, thus inside the combustion chamber results in decreasing temperature rise for the equivalent amount heat release. The EGR system shown in Fig. 1:

$$
\begin{aligned}
& \% E G R=\left\{\left(\text { Volume of } E G R^{*} 100\right) /(\text { Total }\right. \\
& \text { intake charge into cylinder })\}
\end{aligned}
$$

Quantity of exhaust gas that is to be dispersed should be thoroughly monitored; otherwise it would result in lowering the engine efficiency.

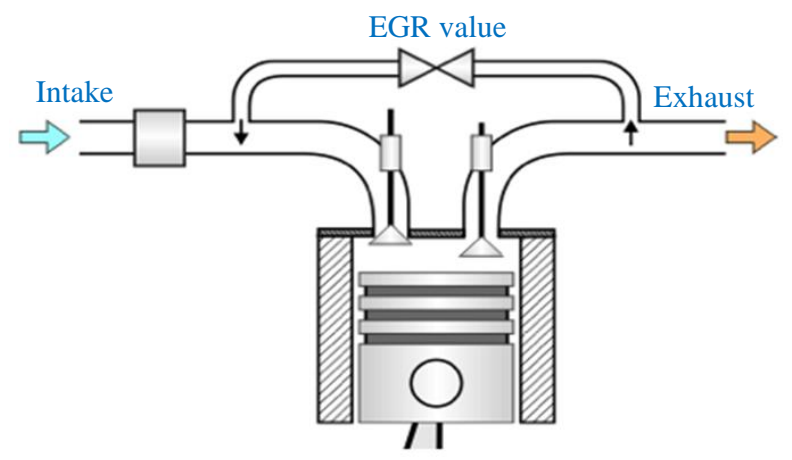

Fig. 1: EGR System (Copyright of Yanmar Co. Ltd.,)

Pongamia oil has been derived from the seeds of the Millettiapinnate tree, which is inhabitant to tropical and moderate Asia. This oil has very close or similar properties to that of diesel fuel, because of which it has been selected for investigation. 
The basic properties of pongamia oil are almost alike to diesel fuel, then, pongamia oil and diesel were run in the CI engine as test fuels and its emission and performance variables of the engine were evaluated. The trial results disclose that biodiesel showed the improved emission parameters to that of diesel. The output power of pongamia biodiesel was comparable with diesel oil (Arul Nicholas et al., 2019).

The evaluation of CI engine by EGR with mixed fuels has carried-out. The effect on BP, BSFC, BTE has reported. Additionally, features of response surface methodology on minimization of NOx, smoke and BSFC has been carried out using mixed oil, EGR \%, injection timing, etc., (Dubey et al., 2019).

CI setup operated in laboratory under peak load $(85 \%$ of full load), unchanging speed (2000 rpm) and a variety of EGR rates $5-40 \%$ (with $5 \%$ rise). Various evaluations like oil run, EGT, emission and exhaust smoke test was done. The consequences show superior fuel cutback and decreased pollution intensity for the low heat rejection unit. The outcome revealed that, at 5\%-EGR with TB10, both NOx and smoke were decreased by 26 and $15 \%$, correspondingly. In addition, TB-20 along with 10\%EGR was also able to decrease both NOx and smoke emission by 34 and $30 \%$, correspondingly contrast to baseline with no EGR (Modi et al., 2018).

The pongamia is mixed with diesel in the different proportions like B0, B20, B40 and B100 with the variation in injection pressures like 180 and 200 bar and \%EGR at 5 and $10 \%$. Resulted that pongamia biodiesel blend (B40) indicated slight raise in BTE with the decline of exhaust gas temperature and also less fuel consumption. Additionally, established that there exists minor fall in emissions. Concluded that pongamia biodiesel (B40) utilized as, replacement fuel for DICI engine without major alterations (Banashankari Nimbaland and Navindgi, 2018).

The analysis of key scientific features measured throughout modeling of piston ring-liner lubrication and friction losses examinations. Survey emphasizes outcomes of piston-ring dynamics, lubricant rheology, parts geometry, surface topography and assumed methods, over frictional losses involved by the piston ring-pack (Delprete and Razavykia, 2017). Therefore, analysis is dedicated to illustrate the synthesis of major technical features, study hard work, summary and obstacles that should be emphasized concerning piston skirt/liner lubrication and piston movements and strike (Delprete and Razavykia, 2018). Piston secondary movement is estimated by lubrication theory and equilibrium of forces and moments, to study the effect of wrist pin position, piston skirt/liner clearance and oil rheology. Numerical technique and finite dissimilarity scheme utilized to describe piston peculiarity and hydrodynamic pressure over the skirt (Delprete et al., 2019).

Ignition delay, increased heat capacity and mixing of inducted charge with noble gases are the three different famous explanations which are quite influential with EGR in case of NOx reduction. EGR causes an increase in ignition delay which leads to the retarding in the timing of injection. The heat capacity premise determines that dispersion of engine exhaust gases through the intake fresh charge uplifts the heat capacity which ultimately lowers high combustion temperature. According to dilution hypothesis, increasing the amount of noble gases in the combination decreases adiabatic flame temperature thus resulting in reduced NOx formation in the engine cylinder (Holman, 2002).

Experimental explorations reveal that BTE is little raised and BSFC is reduced at low loads with EGR contrast to without EGR. But at superior loads, BTE and BSFC are roughly alike with EGR than with no EGR. EGT is reduced with EGR, but NOx reduces considerably. Practically found that $15 \%$-EGR rate effective to reduce NOx substantially with no worsening unit performance (Hussain et al., 2012).

Diverse approaches are utilized to reduce the NOx emission. In this study EGR technique is utilized the CI engine with B20 biodiesel as fuel. Madhua oil is employed to prepare the bio-diesel. Tests executed on one-cylinder, 4-stroke, $\mathrm{H}_{2} \mathrm{O}$-cooled, DI CI engine with EGR and without EGR at various level (5, 10, 15 and $20 \%)$. The outcome reveals that NOx emission is reduced using EGR for diesel and bio-diesel (Manieniyan and Sivaprakasam, 2013).

The systems that are affected by the application of EGR are: BSFC, lubricating system, diesel engine combustion characteristics, the BTE, the combustion parameters of DI $\mathrm{CI}$ engines, speed, $\mathrm{CO}_{2}$ and $\mathrm{HC}$ emissions, the performance characteristics of turbocharged CI engine, fuels, temperature, on EGR rates, the durability of engine components and cooled EGR and the challenges of cooled EGR (Semakula and Inambao, 2017).

The trial setup is run by corn seed oil bio-diesel mixture. Specific features are explored at diverse EGR ratios $(5,10$ and 15\%) and consequences are contrasted with baseline. From the synthesis of the trial outcomes, it is summarized that the NOx are reduced by raise in EGR-ratio (Ramakrishna et al., 2020).

The \%EGR flow rate of mass ranged 0 to $20 \%$ graduated in intervals of $5 \%$. During this experiment all the tests were conducted at constant $1500 \mathrm{rpm}$, to examine outcomes of EGR on emission and performance when useless-cooking oil is applied together through diesel blends (Rao et al., 2015).

The test-rig of the ethanol-fueled diesel engine (EFDE) by EGR is formed. Utilizing above unit, the specific variables of EFDE in dissimilar situations of EGR (ethanol + coating, ethanol + coating + 10\%EGR, ethanol + coating + 20\%EGR) are done. Wholly, it is proved that deviation in the \%EGR rates has a major influence on all above characteristics of EFDE (Saravanan et al. 2020). 
To improve the BTE and simultaneous reduce emissions, testing was done with constant rate of EGR $10 \%$ attached to low heat rejection CI unit improved via 8 YSZ (8\% mol. yttria-stabilized zirconia) ceramic material layered cylinder head and liner fuelled by minimal blend B85A15 by vol. (Karanja based bio-diesel $85 \%$ + additive diethyl ether $15 \%$ ). The outcomes reveal that advancement of injection timing considerably enhanced all the explored variables except NOx for both the engines and in contrast to best outcomes are $6.5 \%$ improvement in BTE with the decrease of $4.5 \%$ brake specific energy consumption, 44\% PM and $18.5 \%$ in NOx found for LHR unit fuelled by B85A15 at 330 BTDC with an $80 \%$ load contrast to RE with baseline. The best arrangement of $\mathrm{RE}$ found to be baseline at injection timing 310 BTDC through $80 \%$ load (Vamsi Krishna et al., 2018).

Engine alteration by decreasing Nozzle Hole Diameter (NHD) (i.e., from the normal value of 0.28 to the adapted value of $0.20 \mathrm{~mm}$ ) revealed as an effectual approach in developing engine parameters. But, it also leads to considerable rise in NOx as a key challenge. Study was intended at beating challenge by applying of a partly-cooled EGR setup. Further particularly, Mahua oil bio-oil mixture (B20) and pure diesel tested on a changed CI engine over 5 different engines loads and in the existence of unstable EGR rates. Wholly findings of examination, the designed engine alteration in the existence of partly-cooled $10 \%$ EGR rate could be suggested as favorable combustion conditions for $20 \%$ mix of Mahua oil and diesel (Kumar et al., 2018).

A review of the literature indicates various ways to improve performance and emissions reduction.
The few gaps/objectives that can be drafted from the above reviews are as follows:

- The investigation is carried out under fixed operating conditions like injection pressure 200bar, CR17.5 and 20\%EGR

- The pongamia is mixed with diesel in the different proportion like B60

- Very less research on the combination of EGR system with pongamia-biodiesel

- Temperature reduction for exhaust gases recirculated in EGR system was neglected

\section{Experimental Setup}

A one cylinder, $\mathrm{H}_{2} \mathrm{O}$ cooled, four stroke, constant speed, DICI engine is utilized for the experimentation conducted depicted in Fig. 2. The features of experimented test rig were represented in Table 1.

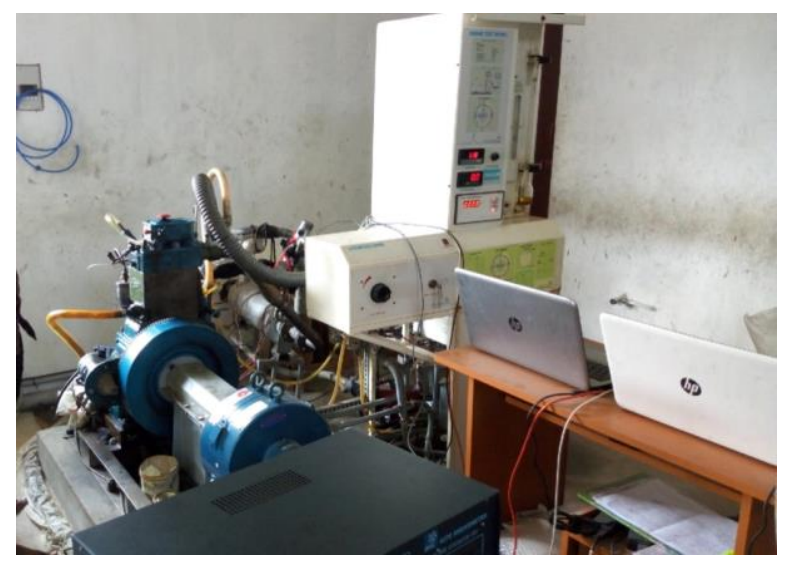

Fig. 2: Single cylinder Kirloskar diesel engine

Table 1: Technical description

\begin{tabular}{ll}
\hline Engine testing (Product code) & One-cylinder, 4-stroke and Diesel Fuel (224) \\
\hline Engine Make & Kirloskar made (Model TV1-Type) \\
Power & Produces $5.2 \mathrm{~kW}, 1500 \mathrm{rpm}$, stroke length of 110mm, cylinder dia. of $87.5 \mathrm{~mm}$, \\
& connecting rod length $234 \mathrm{~mm}$, crank radius $55 \mathrm{~mm}, 661 \mathrm{cc}, \mathrm{CR} 17.5$ \\
Dynamometer & Eddy current \\
Air box & Mild Steel \\
Fuel tank & Glass column for fuel metering with capacity of 15 litters \\
Calorimeter & Pipe-in-pipe \\
Piezo sensor & Capacity of 5000PSI \\
Data acquisition device & NI USB-6210, 16-bit, 250kS/s \\
Piezo powering unit & Model AX-409 \\
Temperature sensor & K- Type. \\
Temperature transmitter & Two wires, RTD, Range 0-100 ${ }^{\circ} \mathrm{C}$ \\
Load indicator & Range 0-50 Kg, Supply 230VAC \\
Load sensor & Strain gauge, ranges from 0-50 Kg \\
Fuel flow transmitter & Type-DP, Ranges from 0-500 mmWC \\
Air flow transmitter & Pressure transmitter, Range (-) 250 mmWC \\
Software & "Engine soft” Engine performance analysis software \\
Rotameter & $40-400$ LPH \\
Optional & Computerized Diesel injection pressure measurement \\
\hline
\end{tabular}




\section{Experimental Methodology}

After all precautions, the test-rig is started and achieved idling state at speed $1500 \mathrm{rpm}$.

Simultaneously, all analyzers and meters for measurements are turned-on and the proper arrangements and settings for measurements are performed with suggested ways as per manufacturer's direction manual.

Once steady condition achieved, preparations and settings for the parameters are recorded through computer for following trials.

Trials are conducted at $20 \%$ EGR with different load conditions like $0,25,50,75$ and $100 \%$ load. The speed at all loads is adjusted to stable value (i.e., $1500 \mathrm{~mm}$ ).

The above conditions, methods of procedures are repeated for the experiments with diesel and diesel blended fuels.

After the experimentation with proposed blends of fuels, the data calculations and analysis were carried out.

\section{Results and Discussion}

The presentation of the test-rig determined in terms of Brake Specific Fuel Consumption (BSFC), Brake thermal efficiency (BTE), Air/fuel ratio, Volumetric Efficiency (VE) and Exhaust Gas Temperature (EGT) and Mechanical Efficiency (ME).

The emission contents of the engine were calculated in terms of $\mathrm{CO}, \mathrm{HC}, \mathrm{NOx}$ and Smoke opacity.

\section{Performance Parameters}

\section{Brake Thermal Efficiency}

Figure 3 shows variation of BTE and \%FLBP for PME blends compared with diesel. Results showed BTE for base is higher than any of the blends. The BTE is less for blend of PME because of less calorific value, higher viscosity and higher density. Higher viscosity results decreased fuel-breakup, vaporization and combustion hence decreased BTE for PME blend. BTE is low at low values of load and is increasing with rise of load for all blends of fuel causes to increase of brake power. For PME60 BTE is high at all loads values compared with all other blends and close to diesel. Hence for PME60 and PME20 the BTE is good.

Under $100 \%$ load operation, BTE for diesel is $32.25 \%$. For PME blends, they were observed to be 31.64, 30.56 and $31.44 \%$ for PME20, PME40 and PME60 respectively.

\section{Brake Specific Fuel Consumption}

Figure 4 shows deviation of BSFC and \%FLBP for $\mathrm{PME}$ combinations compared with diesel. BSFC is factor that indicates how resourcefully an engine is transforming fuel into work. The fuel consumption of an engine based mainly upon heating value of fuel, air/fuel ratio. The calorific value of diesel is more than calorific value of PME and its blend, higher the calorific value higher the heat released through burning and hence higher will be thermal efficiency. Lower calorific value of PME its blend leads to injection of superior quantity of fuel for same power output in contrast to diesel. It is clear from Fig. 4 that at all loads BSFC is more for blends of PME as compared to diesel. BSFC decreases with the increasing loads. This is due to more loads, cylinder wall hotness rose which reduce ignition delay and lead to improved combustion and reduced fuel consumption. It is observed that BSFC chased precisely overturn movement as that of BTE and decrease by the increase of engine load.

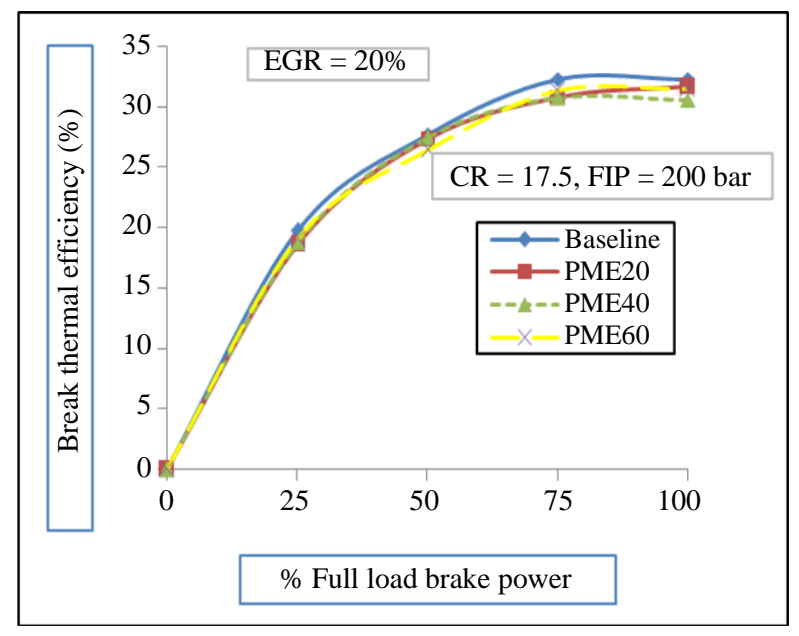

Fig. 3: BTE Vs \%FLBP

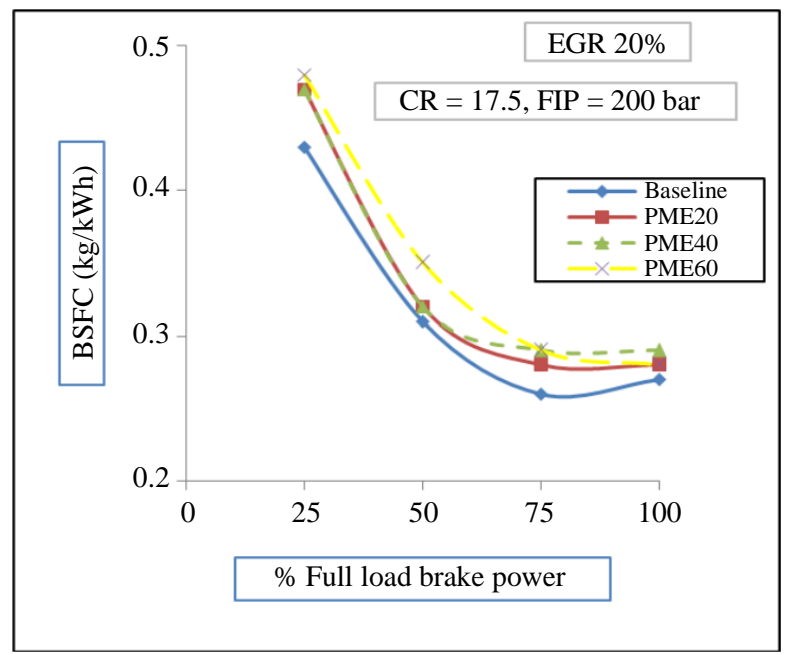

Fig. 4: BSFC Vs \%FLBP 


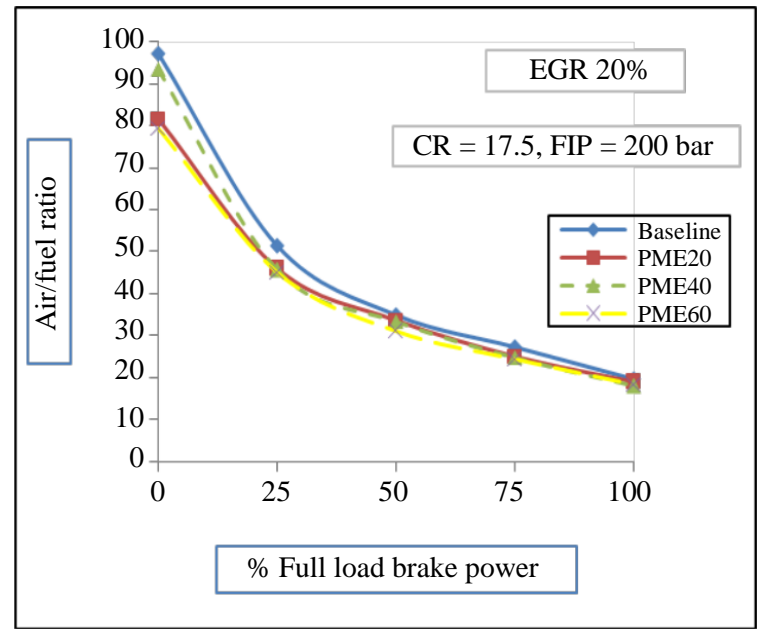

Fig. 5: Air/Fuel ratio Vs \%FLBP of the engine

Under $100 \%$ load operation, BSFC of diesel 0.27 $\mathrm{kg} / \mathrm{kWh}$. For PME20, PME40 and PME60, they were observed to be $0.28,0.29$ and $0.28 \mathrm{~kg} / \mathrm{kWh}$ respectively.

\section{Air/Fuel Ratio}

Figure 5 shows deviation of Air/Fuel ratio and \%FLBP for PME blends in comparison with diesel. It is observed that, under $100 \%$ load operation, Air/Fuel ratio for diesel is $19.55 \%$. For PME20, PME40 and PME60, they were observed to be 18.97, 17.99 and $18.39 \%$ respectively.

\section{Volumetric Efficiency}

Figure 6 shows variation of VE and \%FLBP for neat PME in comparison with petro-diesel. The efficiency is high at low load and then start decreasing on increasing the load with all fuels. It is due to existence of $\mathrm{O}_{2}$ in blend, assists in complete burning of oil even at peak loads thus liberates additional heat leads heating up of manifold and thus, decreases VE.

Volumetric efficiency for diesel is $78.29 \%$. For PME20, PME40 and PME60, they were observed to be $78.03,77.83$ and $77.72 \%$ respectively.

\section{Exhaust Gas Temperature}

Figure 7 shows EGT variation and \%FLBP for neat PME in comparison with diesel. It is due to higher fuel expenditure of blend.

Despite the fact that heating value of blend is poorer than diesel, more exhaust temperatures are credited to the existence of $11 \% \mathrm{O}_{2}$ in fuel which helps in entire burning. EGT for all the oils rises with raise in the load. Quantity of oil introduced raises with load to sustain output power and hence the heat release and EGT increase with rise in load. EGT is important feature for burning in chamber.

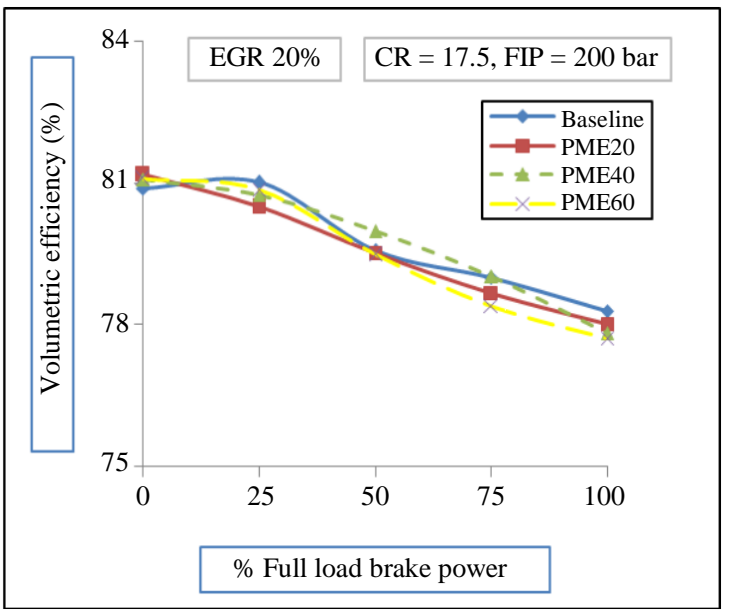

Fig. 6: Volumetric efficiency Vs \%FLBP of the engine

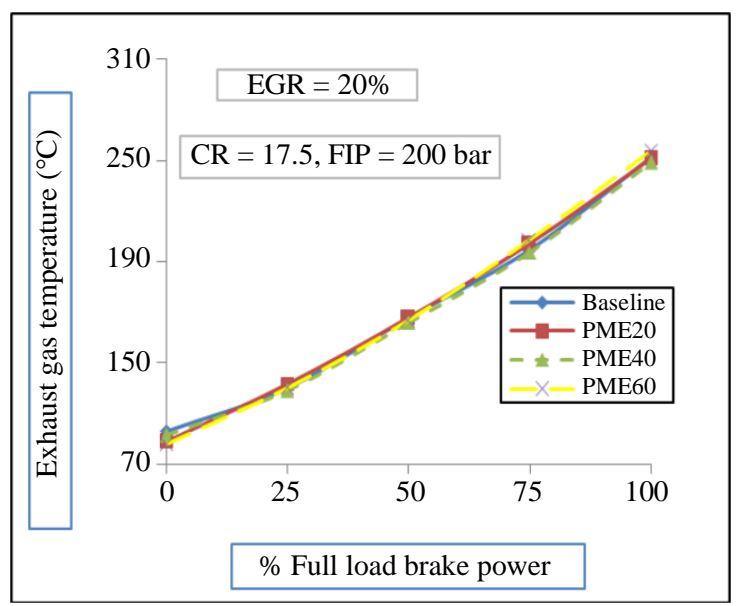

Fig. 7: EGT Vs \%FLBP of the engine

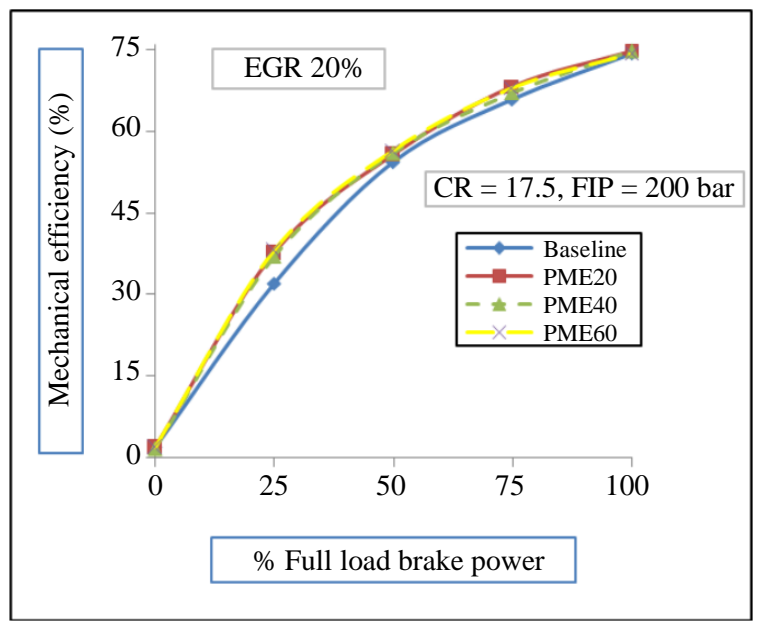

Fig. 8: Mechanical efficiency Vs \%FLBP of the engine

It is observed that, under $100 \%$ load operation EGT for diesel is $251.74^{\circ} \mathrm{C}$. For PME20, PME40 and PME60, 
they were observed to be $251.13^{\circ} \mathrm{C}, 248.83^{\circ} \mathrm{C}$ and $256.05^{\circ} \mathrm{C}$ respectively.

\section{Mechanical Efficiency}

Figure 8 depicts ME variation and \%FLBP neat PME in comparison with petro-diesel. For all bio-diesel mixtures and diesel tested, mechanical efficiency always increases with rise in brake power, on the other hand Mechanical efficiency decreasing with increasing in the bio-diesel blend concentration.

Under $100 \%$ load operation, mechanical efficiency for diesel is $74.31 \%$. For PME20, PME40 and PME60, they were observed to be $74.87,74.73$ and $74.31 \%$ respectively.

\section{CO Emission}

Figure 9 shows the $\mathrm{CO}$ Emission variation with percentage full load brake power (\%FLBP) neat PME compared with neat diesel. Under $100 \%$ load operation, $\mathrm{CO}$ emission for diesel is $0.278 \%$ maximum. Whereas for PME blends, they were observed to be $0.251,0.241$ and $0.277 \%$ for PME20, PME40 and PME60 respectively.

\section{HC Emission}

Figure 10 shows the $\mathrm{HC}$ Emission variation with percentage full load brake power (\%FLBP) for neat PME in comparison with diesel. Under $100 \%$ load operation, HC emission for diesel was 49 PPM. Whereas for PME blends, they were observed to be 59 PPM is maximum, 58 PPM and 58 PPM for PME20, PME40 and PME60 respectively.

\section{NOx Emission}

Figure 11 shows the NOx Emission variation with percentage full load brake power (\%FLBP) neat PME in comparison with diesel. Under $100 \%$ load operation, NOx emission for diesel was1410 PPM maximum. Whereas for PME blends, they were observed to be 1338 PPM, 1391 PPM and 1375 PPM for PME20, PME40 and PME60 respectively.

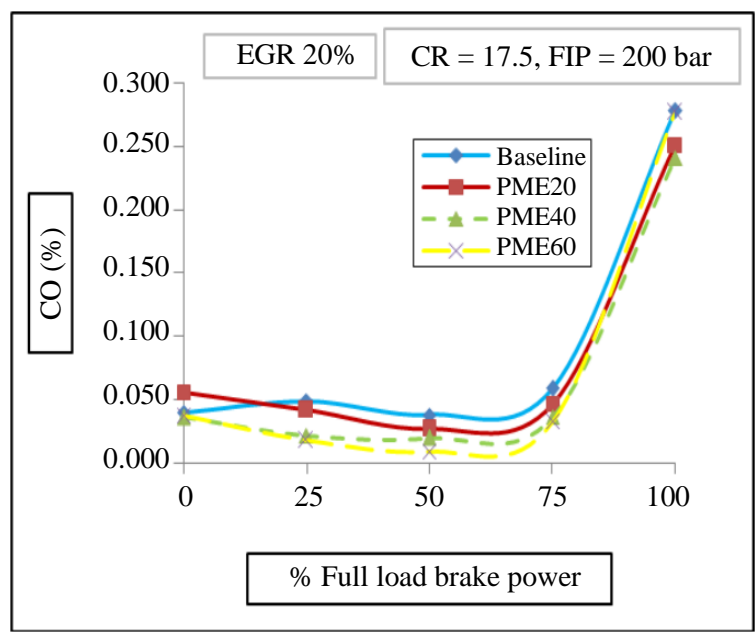

Fig. 9: CO Emission Vs \%FLBP of the engine

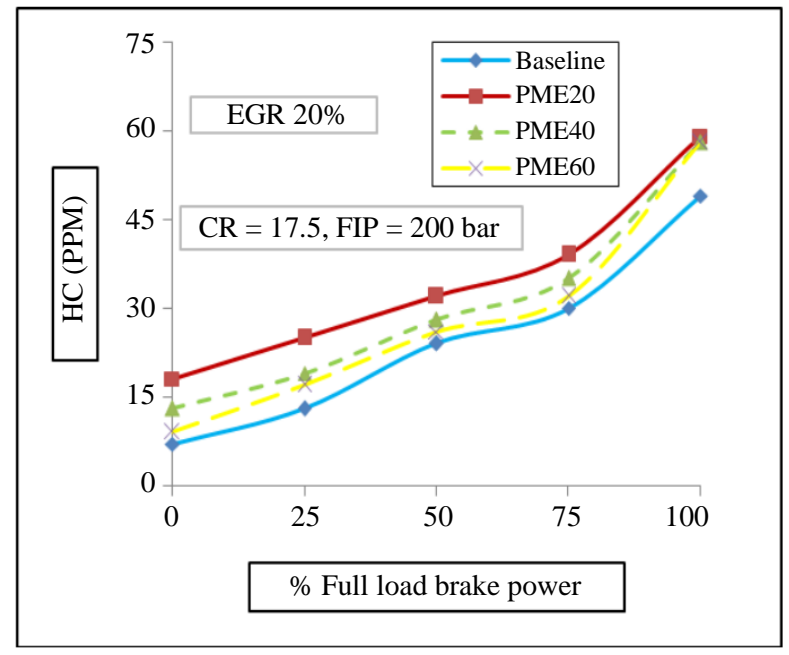

Fig. 10: HC Emission Vs \%FLBP of the engine

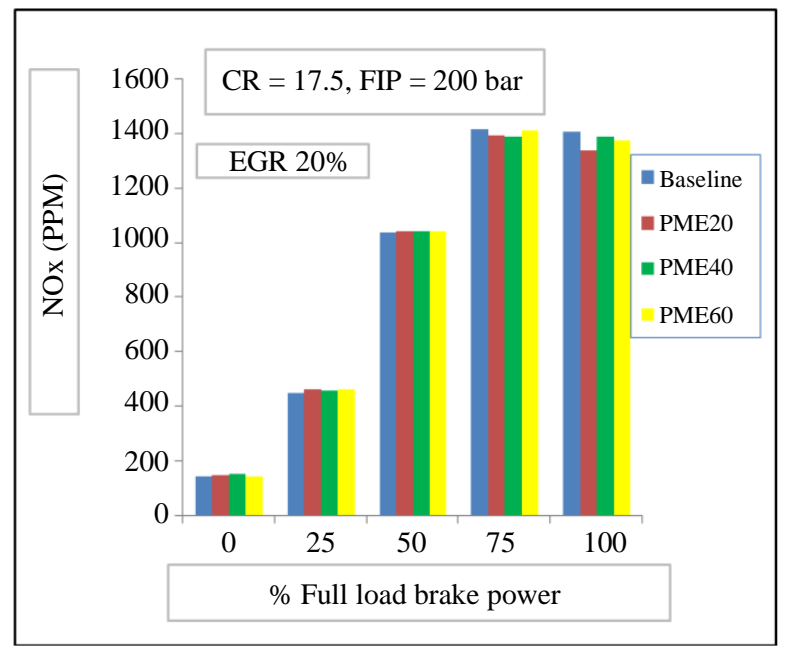

Fig. 11: NOx Emission Vs \%FLBP of the engine

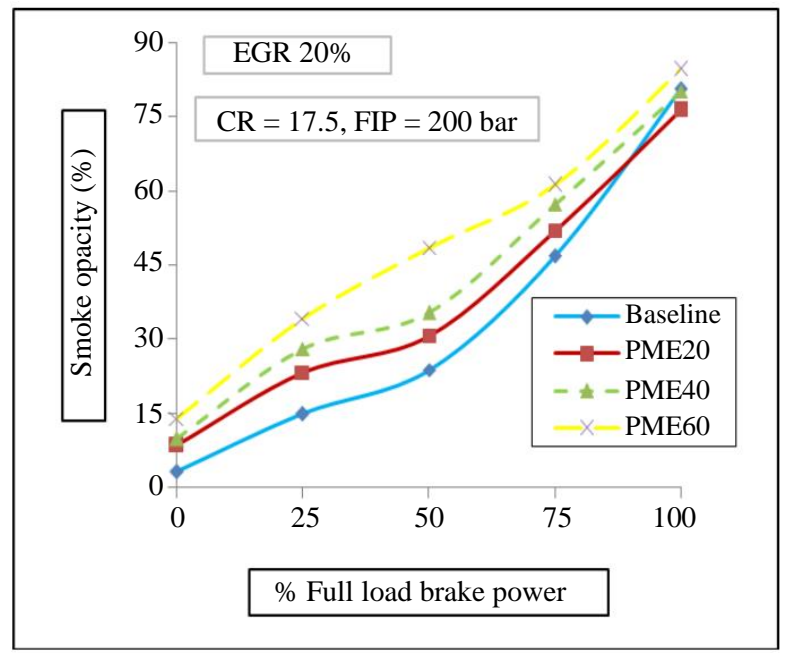

Fig. 12: Smoke Opacity Vs \%FLBP of the engine 


\section{Smoke Opacity}

Figure 12 depicts variation of Smoke-Opacity and $\%$ FLBP for PME in comparison with diesel. Under $100 \%$ load operation, Smoke Opacity for diesel is $80.6 \%$ maximum. For PME blends, observed to be 76.4, 80.3 and $84.6 \%$ for PME20, PME40 and PME60 respectively.

\section{Conclusion}

From the above investigation the utilization of diesel and pongamia blends as replacement fuel for CI engine, the subsequent specific outcomes are drawn.

At $100 \%$-load condition Minute reduction in BTE of PME blends when compared to diesel. For PME20 PME40and PME60 BTE is very close to diesel throughout the engine operation.

All PME blends BSFC increases slightly contrast to diesel-oil throughout the test-rig operation.

Decrease in Air/Fuel ratio observed for all PME blends throughout the engine operation compared to base line.

The VE was comparatively low for all PME blends compared to base line at peak load. Whereas VE comparatively high for all PME blends compared to base line at low load.

The exhaust gas temperature remains almost same for all PME blends throughout the engine operation compared to base line. But slightly increased for PME60 blend under more load.

The ME increased for all PME mixtures throughout the engine operation compared to base line.

Percentage-CO was reduced for every PME combinations mixtures throughout the engine operation.

The quantity of $\mathrm{HC}$ was reduced with rise in concentration of PME. Compared to diesel little increase of $\mathrm{HC}$ for different PME mixtures throughout the engine operation.

Under all loads there exists absolute decrease in NOx emission for every PME combinations.

The \%smoke-opacity was almost similar at peak load for PME60. But very little rise in \%smoke-opacity throughout the engine operation for all PME blends.

From the above conclusions it is clear that PME60 has similar or significant impact on performance and emission parameters compared with baseline.

\section{Acknowledgement}

Authors acknowledge the Qassim University, College of Engineering Unaizah in extending Lab services to perform the experimentation.

\section{Authors Contributions}

Abdullah Al-Ghafis: Experimental data collection, plotting the graphs, collecting the literature reviews journal papers and final proof reading. Response to reviewers comments.

M Shameer Basha: Writing manuscript as per the format.

\section{Ethics}

This script is unique and includes private matter. Authors states that no ethical concerns may occur after publication of document.

\section{References}

Arul Nicholas, T., Venkatakrishna, A., Joy, N., \& Mariadhas, A. (2019). Performance and emission analysis on diesel engine fuelled with neat pongamia biodiesel. International Journal of Ambient Energy, 1-7.

Banashankari Nimbaland \& Navindgi, M. C. (2018). Experimental Investigation of Methods to Improve Performance of DI Engine using Pongamia Biodiesel by Varying Parameters. Int. Research J of Eng. and Tech., Volume: 05 Issue: 05.

Delprete, C., \& Razavykia, A., (2017). Piston ring-liner lubrication and tribological performance evaluation: A review. J Eng. Tribology.

Delprete, C., \& Razavykia, A., (2018). Piston dynamics, lubrication and tribological performance evaluation: A review. Int. J of Engine Research.

Delprete, C., Razavykia, A., \& Baldissera, P. (2019). Detailed analysis of piston secondary motion and tribological performance. International Journal of Engine Research, 1468087419833883.

Dubey, A., Ansari, N. A., Kumar, G., Arora, A., \& Sharma, A. (2019, November). A Review on Performance and Emission of CI Engine using Exhaust gas recirculation (EGR). In IOP Conference Series: Materials Science and Engineering (Vol. 691, No. 1, p. 012028). IOP Publishing.

Holman, J., (2002). Heat Transfer, 9th edition, McGrawHill, New York.

Hussain, J., Palaniradja, K., Alagumurthi, N., \& Manimaran, R. (2012). Retracted: effect of exhaust gas recirculation (EGR) on performance and emission characteristics of a three cylinder direct injection compression ignition engine.

Kumar, M. V., Babu, A. V., Kumar, P. R., \& Reddy, S. S. (2018). Experimental investigation of the combustion characteristics of Mahua oil biodieseldiesel blend using a DI diesel engine modified with EGR and nozzle hole orifice diameter. Biofuel Res. J, 5(3), 863-871.

Manieniyan, V., \& Sivaprakasam, S. (2013). Experimental analysis of exhaust gas recirculation on DI diesel engine operating with biodiesel. International Journal of Engineering and Technology, 3(2), 129-135. 
Modi, A. J., Gosai, D. C., \& Solanki, C. M. (2018). Experimental Study of Effect of EGR Rates on NO $\mathrm{x}$ and Smoke Emission of LHR Diesel Engine Fueled with Blends of Diesel and Neem Biodiesel. Journal of The Institution of Engineers (India): Series C, 99(2), 181-195.

Ramakrishna, R. E., Keerthana, B. V. S., Dhana Raju, V. \& Sai Mahith, A., (2020). Mitigation of $\mathrm{NO}_{X}$ emissions with application of exhaust gas recirculation on diesel engine fuelled with diesel-corn seed oil biodiesel blend. Int. J. of Ambient Energy.

Rao, K. S., Mutyalu, K. B., \& Ramakrishna, A. (2015). Effect of exhaust gas recirculation on performance and emission characteristics of diesel engine fueled with waste cooking oil methyl ester. ARPN Journal of Engineering and Applied Sciences, 10(11), 4799-4804.

Saravanan, P., Kumar, N. M., Ettappan, M. Dhanagopal, R., \& Vishnupriyan, J. (2020). Effect of exhaust gas re-circulation on performance, emission and combustion characteristics of ethanol-fueled diesel engine. Case Studies in Thermal Engineering, 100643.

Semakula, M., \& Inambao, F. (2017). The Effects of Exhaust Gas Recirculation on the Performance and Emission Characteristics of a Diesel Engine-A Critical Review. International Journal of Applied Engineering Research, 12(23), 13677-13689.

Vamsi Krishna, K., Sastry, G. R. K., Krishna, M. V. S. \& Jibitesh Kumar, P. (2018). Performance and Emission analysis of optimal DEE blended Pongamia pinnata L. biodiesel fuelled to EGR coupled Low Heat Rejection (LHR) Diesel Engine. MSandE, 377(1), 012164.

\section{Nomenclature}

$\begin{array}{ll}\text { Notation } & \text { Description } \\ \text { B0 } & \text { Baseline/Neat diesel } \\ \text { PME20/B20 } & 20 \% \text { blend of biodiesel } \\ \text { PME40/B40 } & 40 \% \text { blend of biodiesel } \\ \text { PME60/B60 } & 60 \% \text { blend of biodiesel } \\ \text { B100 } & 100 \% \text { Pongamia methyl ester } \\ \text { BSFC } & \text { Brake specific fuel consumption } \\ \text { BTE } & \text { Brake thermal efficiency } \\ \text { CI } & \text { Compression Ignition } \\ \text { CO } & \text { Carbon monoxide } \\ \text { CO } & \text { Carbon dioxide } \\ \text { CR } & \text { Compression ratio } \\ \text { DICI } & \text { Direct injection compression ignition } \\ \text { EGR } & \text { Exhaust gas recirculation } \\ \text { EGT } & \text { Exhaust gas temperature } \\ \text { FIP } & \text { Fuel injection pressure } \\ \text { FLBP } & \text { Full load brake power } \\ \text { HC } & \text { Hydrocarbons } \\ \text { H } 20 & \text { Water } \\ \text { IC } & \text { Internal Combustion } \\ \text { LPH } & \text { Liter Per Hour } \\ \text { ME } & \text { Mechanical efficiency } \\ \text { NOx } & \text { Oxides of nitrogen } \\ \text { PM } & \text { Particulate matter } \\ \text { PME } & \text { Pongamia Methyl Ester } \\ \text { PPM } & \text { parts per million } \\ \text { PSI } & \text { Pound/Square Inch } \\ \text { VE } & \text { Volumetric efficiency } \\ \text { \%EGR } & \text { Percentage of Exhaust gas recirculation } \\ & \end{array}$

